\title{
Indirect Ultraviolet Detection of Biologically Relevant Organic Acids by Capillary Electrophoresis
}

Hong Chen

Cleveland State University

Yan Xu

Cleveland State University, y.xu@csuohio.edu

Frederick Van Lente

Cleveland Clinic Foundation

Follow this and additional works at: https://engagedscholarship.csuohio.edu/scichem_facpub

¿nhaplof.thel Rnalytical Chemistry Commons

MetroHealth Medical Center

How does access to this work benefit you? Let us know!

\section{Publisher's Statement}

NOTICE: this is the author's version of a work that was accepted for publication in Journal of Chromatography B: Biomedical Sciences and Applications. Changes resulting from the publishing process, such as peer review, editing, corrections, structural formatting, and other quality control mechanisms may not be reflected in this document. Changes may have been made to this work since it was submitted for publication. A definitive version was subsequently published in Journal of Chromatography B: Biomedical Sciences and Applications, [679, 1-2, April 26, 1996 DOI\#10.1016/0378-4347(96)00002-3

\section{Recommended Citation}

Chen, Hong; Xu, Yan; Lente, Frederick Van; and Ip, Michael P.C., "Indirect Ultraviolet Detection of Biologically Relevant Organic Acids by Capillary Electrophoresis" (1996). Chemistry Faculty Publications. 197. https://engagedscholarship.csuohio.edu/scichem_facpub/197 


\title{
Indirect ultraviolet detection of biologically relevant organic acids by capillary electrophoresis
}

\author{
Hong Chen, Yan Xu , Frederick Van Lente, Michael P.C. Ip
}

\begin{abstract}
Indirect UV detection of fourteen short-chain organic acids (e.g., oxalic acid, citric acid, malonic acid, tartaric acid, methylmalonic acid, $\alpha$-ketoglutaric acid, succinic acid, ethylmalonic acid, methylsuccinic acid, glutaric acid, apidic acid, methylglutaric acid, lactic acid and pynuvic acid) by capillary electrophoresis is described. The method used phthalate as the UV-absorbing additive in carbonate buffer and the non-absorbing analytes were detected indirectly at $230 \mathrm{~nm}$. The influences of buffer $\mathrm{pH}$, ionic strength, concentration of phthalate and organic modifier on indirect signal response and migration behavior of the organic acids were investigated. Comparisons of reproducibility on migration time, limit of detection and separation efficiency among three types of capillary (e.g., polyacrylamide-coated, myristyltrimethylammonium bromidecoated and uncoated capillaries) were conducted. The method developed was applied to detect succinic acid, methylmalonic acid, citric acid, glutaric acid and lactic acid in human body fluids, and preliminary results were provided.
\end{abstract}

Keywords: Organic acids; Succinic acid; Methylmalonic acid; Citric acid; Glutaric acid; Lactic acid

\section{Introduction}

Short-chain endogenous organic acids (e.g., oxalic acid, citric acid, malonic acid, tartaric acid, methylmalonic acid, $\alpha$-ketoglutaric acid, succinic acid, ethylmalonic acid, methylsuccinic acid, glutaric acid, apidic acid, methylglutaric acid, lactic acid and pyruvic acid) are found in human serum or urine. Some of these organic acids have known medical significance in relation to their concentrations in biological fluids, since they are intermediates formed at various stages of amino acid or fatty acid metabolism, and may function as indicators of a variety of diseases [1]. Currently, gas chromatography-mass spectroscopy (GC-MS) [2,3] and liquid chromatography $(\mathrm{LC})[4,5]$ are used in clinical laboratories to detect short-chain organic acids in biological fluids. Despite their high analytical sensitivity and specificity, these methods often require laborious sample pretreatment, derivatization and extended separation times. Therefore, a simple, efficient, and reliable analytical method is much needed for analyzing these non-absorbing endogenous organic acids.

Capillary electrophoresis (CE) is maturing into a bona fide analytical technique after a decade of intensive development. It is well suited for separation and detection of a variety of compounds, ranging from small inorganic ions and organic 
molecules to large biochemical molecules [6-8]. Attributed to its high separation efficiency, short analysis time, and low operational cost, CE has tremendous potential in clinical diagnostic assay development $[9,10]$. In this study, we have developed a CE method using indirect UV absorbance detection for determination of fourteen short-chain organic acids. Factors that effect sensitivity of indirect UV detection and migration behavior of organic acids (e.g., buffer $\mathrm{pH}$, ionic strength, organic modifier and the concentration of UV additive) were investigated by using a polyacrylamide-coated capillary and the analytical performances of polyacrylamide-coated, myristyltrimethylammonium bromide-coated (MTAB-coated) and uncoated capillaries were compared. The developed CE method was applied to the analysis of several organic acids in biological fluids.

\section{Experimental}

\section{Chemicals and solutions}

All organic acids were purchased from Sigma (St. Louis, MO, USA) except for succinic acid and oxalic acid which were obtained from Mallinckrodt (St. Louis, MO, USA). MTAB was obtained from Aldrich (Milwaukee, WI, USA). Potassium hydrogen phthalate (KHP), sodium carbonate (anhydrous), methanol, acetic acid (glacial), hydrochloric acid and sodium hydroxide were purchased from Fisher Scientific (Pittsburgh, PA, USA). Ammonium persulfate, $\mathrm{N}, \mathrm{N}, \mathrm{N}^{\prime}, \mathrm{N}^{\prime}$-tetramethylethylenediamine (TEMED), $\gamma$-(methacryloyloxy)propyltrimethoxysilane and acrylamide were obtained from Pharmacia Biotech (Piscataway, NJ, USA).

Aqueous solutions were prepared with deionized water (Barnstead/Thermolyne NANOpure system, Dubuque, IA, USA). Standard stock solutions of organic acids were prepared in deionized water at a concentration of $1.0 \mathrm{mg} / \mathrm{ml}$. Prior to $C E$ analysis, fresh working solutions of various organic acid mixtures were prepared by serial dilution from the stock solutions with deionized water. For the study of phthalate concentration, carbonate-phthalate run buffers ( $5 \mathrm{mM} / 0.1-3.0 \mathrm{~m} M)$ were prepared by dissolving the appropriate amount of sodium carbon- ate and potassium hydrogen phthalate in deionized water and adjusting the $\mathrm{pH}$ to $\mathrm{pH} 7.0$ with $0.1 \mathrm{M}$ $\mathrm{HCl}$. For the $\mathrm{pH}$ study, carbonate-phthalate run buffers $(5 \mathrm{~m} M / 1.5 \mathrm{mM})$ with $\mathrm{pH}$ values from 5.5 to 8.5 were adjusted to the desired values with $0.1 \mathrm{M}$ $\mathrm{HCl}$. For the study of carbonate concentration, carbonate-phthalate run buffers $(1-10 \mathrm{mM} / 1.5 \mathrm{mM})$ were prepared by serial dilution of a carbonatephthalate run buffer $(10 \mathrm{mM} / 1.5 \mathrm{mM})$ at $\mathrm{pH} 7.0$ with $1.5 \mathrm{mM}$ phthalate ( $\mathrm{pH} 7.0$ ). For the study of organic modifier, carbonate-phthalate run buffers $(5$ $\mathrm{m} M / 1.5 \mathrm{~m} M$ ) with methanol concentrations ranging from 0 to $20 \%$ were prepared by diluting the appropriate amount of carbonate $(10 \mathrm{mM})$, phthalate $(0.1 M)$ and methanol in deionized water and adjusting the $\mathrm{pH}$ to $\mathrm{pH} 7.0$ with $0.1 \mathrm{M} \mathrm{HCl}$. In this work, all buffers were filtered through $0.45-\mu \mathrm{m}$ cellulose acetate membrane filters (Alltech, Deerfield, IL, USA) before use.

\section{Capillary columns}

Open tubular fused-silica capillaries (360 $\mu \mathrm{m}$ O.D., $100 \mu \mathrm{m}$ I.D.) with polyimide coating on the outer surface were purchased from Polymicro Technologies (Phoenix, AZ, USA). A new capillary was conditioned by rinsing sequentially with $0.1 M$ $\mathrm{NaOH}$, deionized water and run buffer and this was used as an uncoated capillary. A MTAB-coated capillary was prepared by filling the uncoated capillary with run buffer containing $0.15 \mathrm{~m} M$ MTAB (pH 9.0 ). A polyacrylamide-coated capillary was made using the procedure described by Hjerten and Kiessling-Johansson [11,12], with minor modification. Details are as follows: The inner surface of a 1-mlong capillary was first treated with $1 M \mathrm{NaOH}$ for $30 \mathrm{~min}$, then rinsed with deionized water for $30 \mathrm{~min}$. The pretreated capillary was flushed with a silane solution $(\mathrm{pH} \mathrm{3.5)}$ for $3 \mathrm{~h}$ at room temperature. The silane solution was prepared by adding $50 \mu \mathrm{l}$ of glacial acetic acid and $50 \mu \mathrm{l}$ of $\gamma$-(methacryloyloxy)propyltrimethoxysilane to $9.90 \mathrm{ml}$ of deionized water; the resultant mixture was stirred until it clarified. After washing with methanol and deionized water, the capillary was dried with $\mathrm{N}_{2}$ gas. A monomer solution was prepared by dissolving $0.4 \mathrm{~g}$ of acrylamide in $10 \mathrm{ml}$ of de-aerated deionized water, followed by the addition of $100 \mu \mathrm{l}$ of $10 \%$ 
ammonium persulfate (freshly prepared) and $10 \mu \mathrm{l}$ of TEMED. This solution was then pushed through the silanized capillary continuously for $1 \mathrm{~h}$ using a $\mathrm{N}_{2}$-pressurized capillary wash tube (Alltech). After polymerization, the capillary was flushed with deionized water and was ready for use. This procedure produces a monolayer of linear polyacrylamide on the inner surface of the capillary. By this procedure, electroosmosis inside the capillary was eliminated and possible adsorption of analyte ions onto the capillary surface was minimized.

\section{$C E$ instrument}

A Beckman (Fullerton, CA, USA) P/ACE 2050 CE instrument and an IBM PC with System Gold software were used. This system is equipped with an autosampler, a temperature-controlled capillary cartridge and a UV detector. On-column UV detection was performed at $230 \mathrm{~nm}$ and the capillary temperature was set at $25^{\circ} \mathrm{C}$. Samples were introduced into the capillary either by pressure injection at $3.45 \mathrm{kPa}$ for $5 \mathrm{~s}$ or by electrokinetic injection at $10 \mathrm{kV}$ for 10 $\mathrm{s}$. Between runs, the capillary was rinsed using run buffer for $90 \mathrm{~s}$. Phenol was used as a neutral marker to determine the electroosmotic mobility. If an uncoated capillary was used, the cathode was placed in the outlet side of the capillary and the anode was in the inlet. If MTAB-coated or polyacrylamidecoated capillaries were used, the polarity of the electrodes was reversed.

\section{Sample pretreatment}

Serum and urine specimens used in this study were obtained from the Cleveland Clinic Foundation (Cleveland, OH, USA). For the serum specimen, a partial deproteinization procedure was used, in which $500 \mu \mathrm{l}$ of serum sample was first mixed with $500 \mu \mathrm{l}$ of methanol containing $5 \mu \mathrm{g}$ of ethylmalonic acid (EMA, an internal standard); after vortex-mixing for $2 \mathrm{~min}$ and centrifugation at $560 \mathrm{~g}$ for $15 \mathrm{~min}, 500 \mu \mathrm{l}$ of the supernatant was transferred and dried under $\mathrm{N}_{2}$; the resulting residue was re-dissolved in $250 \mu \mathrm{t}$ of deionized water prior to $\mathrm{CE}$ analysis. For the urine specimen, filtration with a $0.45-\mu \mathrm{m}$ cellulose acetate membrane filter (Alltech) and a five-fold dilution was performed before analysis, and the EMA concentration in the diluted urine was $10 \mu \mathrm{g} / \mathrm{ml}$.

\section{Results and discussion}

\section{Indirect detection in $C E$}

The concept of indirect UV detection was first introduced by Small and Miller in ion chromatography [13], and was used in CE application by Hjerten et al. [14]. Indirect detection in CE has the advantage of being simple to use, since it requires no modification of the basic instrument. Previous reports have been published including indirect photometric detection [14-22], indirect fluorescence detection $[23,24]$ and indirect amperometric detection [25]. Since nearly all CE instruments are equipped with UV detectors, the indirect UV detection method is probably the most practical approach, if the limit of detection of non-UV absorbing compounds is not a major concern.

To achieve indirect UV detection in $\mathrm{CE}$, an electrolyte with strong UV absorptive properties is added to the run buffer to produce a high background absorption in the UV detector. In the absence of non-absorbing analytes, the background signal is constant. If ionic analytes are introduced, they will be separated into separated analyte zones through differential migration inside the separation capillary. Each separated analyte zone displaces UV-absorbing additive ions on a charge-to-charge basis, resulting in a negative peak relative to the high UV absorption baselines. The displaced UV additive is eluted as a system peak with similar retention characteristics to those that would be obtained if the UV additive was injected onto the capillary.

\section{Phthalate as the UV-absorbing additive}

In indirect UV detection, the selection of the UV additive is of the utmost importance. An effective UV additive not only will provide a suitable UV absorbance background at a wide range of wavetengths, but also will provide a close match of ionic mobility with those of analyte ions. A discrepancy in ionic mobility between the UV additive and analytes may result in loss of detection sensitivity and peak 
symmetry, and may cause band-broadening $[15,26]$. Phthalate was chosen as the UV-absorbing additive for this work as it has a dissociation constant and molecular mass that are close to the corresponding values of the organic acids of interests (Table 1). Although phthalate has a higher absorbance at 200 $\mathrm{nm}$ than at $230 \mathrm{~nm}$ (spectrum not shown), a detection wavelength of $230 \mathrm{~nm}$ was used in this work since interference experienced from biological fluids was much less at this wavelength.

\section{Indirect signal response}

There are several factors that affect the sensitivity of the indirect signal response. These include the amount of $\mathrm{UV}$ additive, $\mathrm{pH}$, buffer concentration and the amount of organic modifier present. Using methylmalonic acid (MMA), succinic acid (SUA) and ethylmalonic acid (EMA) as target analytes, we have evaluated the influences of the following factors.

\section{Concentration of phthalate}

The concentration of UV additive determines the magnitude and the linear range of the detection. Fig. 1 shows that a linear response of phthalate in the UV detector of CE system was obtained from 0 to 1.5 $\mathrm{m} M$; whereas the magnitudes of response of the three organic acids studied increased as the con-

Table 1

Dissociation constants of some organic acids [27,28]

\begin{tabular}{lcccc}
\hline Organic acid & $M_{\mathrm{r}}$ & $\mathrm{p} K_{a_{1}}$ & $\mathrm{p} K_{a_{2}}$ & $\mathrm{p} K_{a_{3}}$ \\
\hline Oxalic acid & 90.04 & 1.23 & 4.19 & \\
Citric acid & 192.1 & 3.14 & 4.77 & 6.39 \\
Malonic acid & 104.1 & 2.83 & 5.69 & \\
Tartaric acid & 150.1 & 2.98 & 4.34 & \\
Methylmalonic acid & 118.1 & 3.07 & 5.87 & \\
$\alpha$-Ketoglutaric acid & 146.1 & 3.10 & $\mathrm{NA}$ & \\
Succinic acid & 118.1 & 4.60 & 5.61 & \\
Ethylmalonic acid & 132.1 & 2.90 & 5.55 & \\
Methylsuccinic acid & 132.1 & 4.13 & 5.64 & \\
Glutaric acid & 132.1 & 4.31 & 5.41 & \\
Apidic acid & 146.1 & 4.43 & 5.41 & \\
Methylglutaric acid & 146.1 & 4.24 & 5.41 & \\
Lactic acid & 88.06 & 3.86 & & \\
Pyruvic acid & 90.08 & 2.50 & & \\
Phthalic acid & 166.1 & 2.89 & 5.51 & \\
\hline
\end{tabular}

NA: Not available.

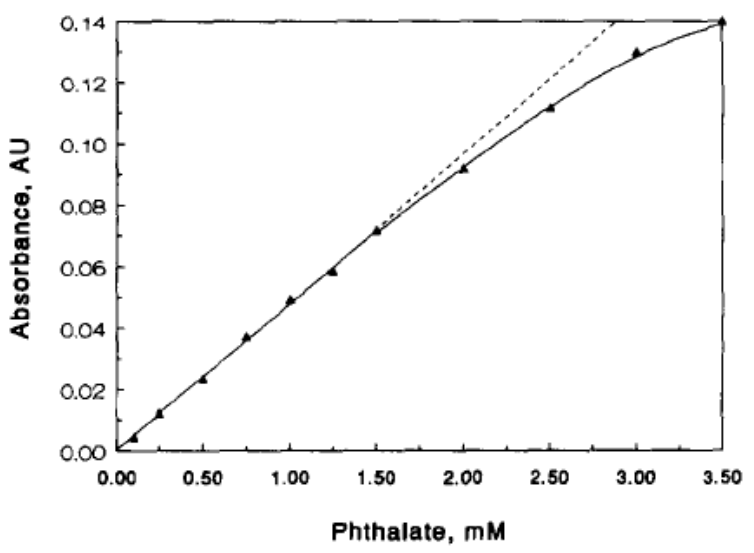

Fig. 1. Absorbance vs. phthalate concentration. Experimental conditions: polyacrylamide-coated capillary, $67 \mathrm{~cm} \times 100 \mu \mathrm{m}$ (I.D.); temperature, $25^{\circ} \mathrm{C}$; UV filter, $230 \mathrm{~nm}$; buffers, $5 \mathrm{mM}$ carbonate $/ 0.1 \mathrm{mM}$ to $3.5 \mathrm{mM}$ phthalate at $\mathrm{pH} 7.0$. The experiment was done by sequentially pushing eleven buffers containing various amounts of phthalate through the separation capillary.

centration of phthalate increased and reached maximum at $2 \mathrm{~m} M$ phthalate (Fig. 2A). Accordingly, 1.5 $\mathrm{m} M$ phthalate was chosen as the concentration of UV additive for later work in order to retain a linear detection response with maximum detection sensitivity.

\section{Buffer $p H$}

The $\mathrm{pH}$ influences the degree of dissociation of buffer ions and UV additives, as well as of organic acids; therefore, it effects the apparent mobilities of ionic species in $\mathrm{CE}$ and the indirect signal response. Fig. 2B shows that the signal responses of organic acids were high at a $\mathrm{pH}$ of 5.5 and decreased with increasing $\mathrm{pH}$ values. More notable decreases in signals were detected between $\mathrm{pHs} 6.0$ and 7.5 . At pHs of between 7.5 and 8.5 , the responses remained relatively constant $(\mathrm{pHs}$ higher than 8.5 were not used due to the instability of the polyacrylamide coating). To understand what happened in Fig. 2B, it is necessary to comprehend the charge displacement of the UV additive by analyte ions in a CE environment, as described in the following discussion. Under separation conditions, the run buffer containing the UV additive and analyte ions migrates at different rates towards the outlet of the capillary. While the separated analyte ions displaced the UV additive ions in a capillary zone, they also displaced 

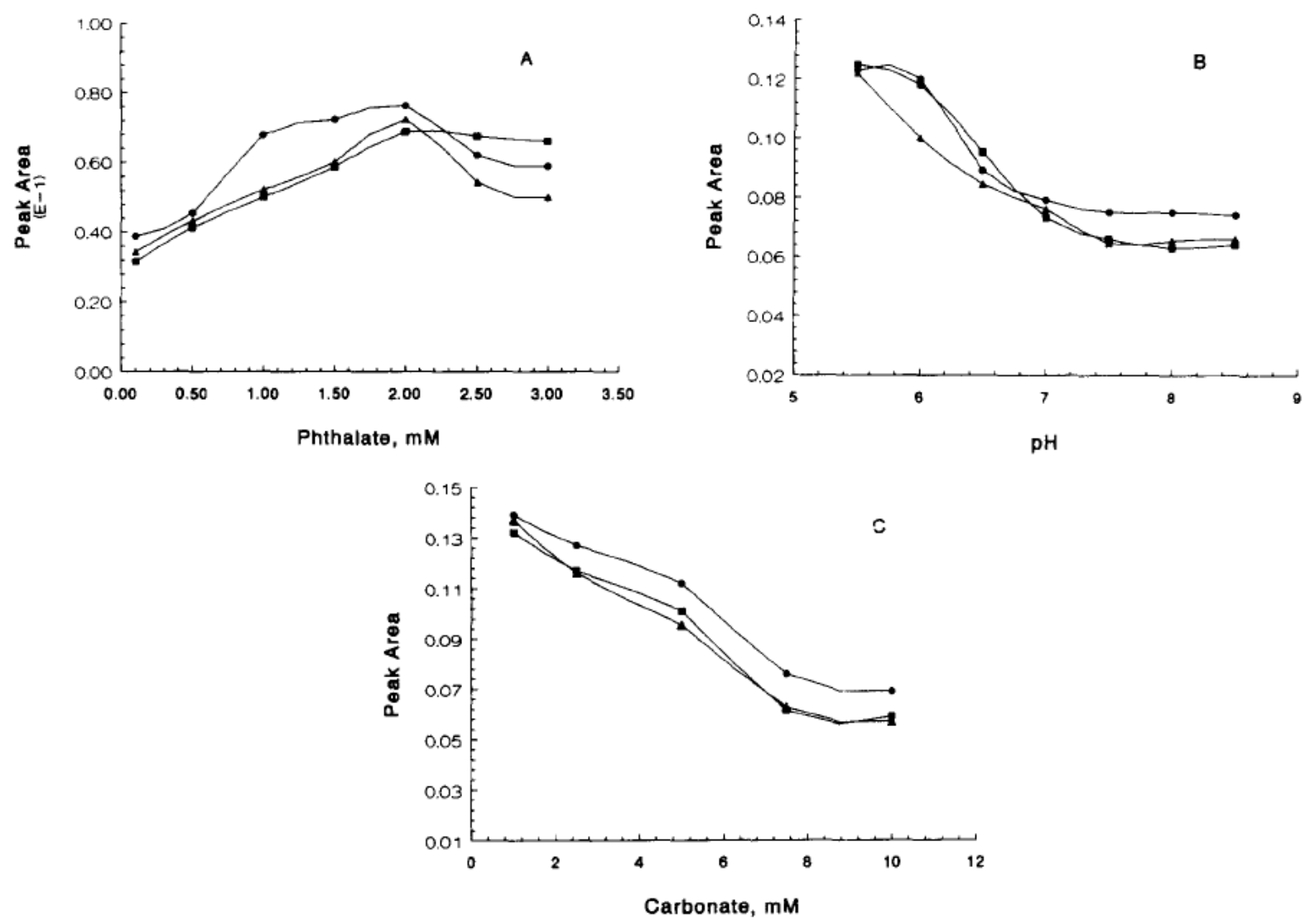

Fig. 2. Factors effecting indirect UV response. (A) Phthalate concentration, (B) buffer $\mathrm{pH}$ and (C) carbonate concentration. Experimental conditions: polyacrylamide-coated capillary, $67 \mathrm{~cm} \times 100 \mu \mathrm{m}$ (I.D.), temperature, $25^{\circ} \mathrm{C}$ : UV filter, $230 \mathrm{~nm}$ : separation potential. $15 \mathrm{kV}$ :

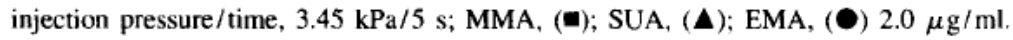

other co-ions of the same charge (e.g., buffer ions). Therefore, the net charge of an analyte in a separated zone equals the total charge of the UV additive and other co-ions being displaced, and the magnitude of the signal response at the detector is directly proportional to the ratio of the UV additive vs. other co-ions in the displaced zone. This principle can be demonstrated by a dilution experiment (data not shown) in which a run buffer containing $5 \mathrm{mM}$ carbonate and $2.0 \mathrm{mM}$ phthalate was stepwise diluted to $25 \%$ of its original concentration and the signal response of an organic acid, EMA, remained almost the same. Therefore, the variations of signal response in Fig. 2B were attributed to the changes in the sub-populations of the buffer ions (e.g., $\mathrm{HCO}_{3}^{-}$and $\mathrm{CO}_{3}^{2-}$ ) along with the $\mathrm{pH}$ changes. As the $\mathrm{pH}$ increased from 5.5 to 7.5 , the amount of carbonate
( $\mathrm{p} K_{a_{1}}=6.34, \mathrm{p} K_{a_{2}}=10.34$ ) in the form of $\mathrm{HCO}_{3}^{-}$ increased from 12.6 to $93.5 \%$. As a result, the ratio of UV additive to co-ions in the capillary zone decreased, as does the magnitude of the indirect response.

\section{Buffer concentration}

The effect of buffer concentration on indirect response was shown in Fig. $2 \mathrm{C}$, using carbonate buffer as the run buffer. Because the signal response in indirect detection is directly related to the ratio of the UV additive to the concentration of co-ions, the response decreased as the buffer concentration increased, even though the concentration of the UV additive remained constant. Therefore, to maximize the detection sensitivity, the run buffer concentration 
should be maintained at the lowest possible level. Accordingly, $5 \mathrm{~m} M$ carbonate was chosen as the concentration for subsequent studies.

\section{Influence of organic modifier}

There were no apparent changes in the indirect signal response upon the addition of 0 to $20 \%$ methanol (results not shown). There may be an insignificant effect of methanol on the dissociations of carbonic acid and phthalic acid, as well as on the charge properties of the buffer system. Hence, the ratio of phthalate to bicarbonate remained unaffected.

\section{Migration of organic acids}

Once the polar silanol groups on the inner surface of a capillary are covered by linear polyacrylamide, electroosmosis that flows in the opposite direction to electrophoresis of an anion will be eliminated. The migration order of organic acids is then solely dependent on their electrophoretic mobilities which are buffer concentration-, $\mathrm{pH}$ - and organic modifierdependent.

\section{Buffer concentration}

The effect of buffer concentration on mobility has been well studied [29]. In general, electrophoretic mobility is inversely proportional to the viscosity of the buffer and to the square root of the buffer concentration (i.e., higher buffer concentrations result in slower mobility and longer migration times of an analyte). Interestingly, our experimental results indicated otherwise. The migration times of the organic acids either decreased with increasing carbonate buffer concentration (Fig. 3A), or remained
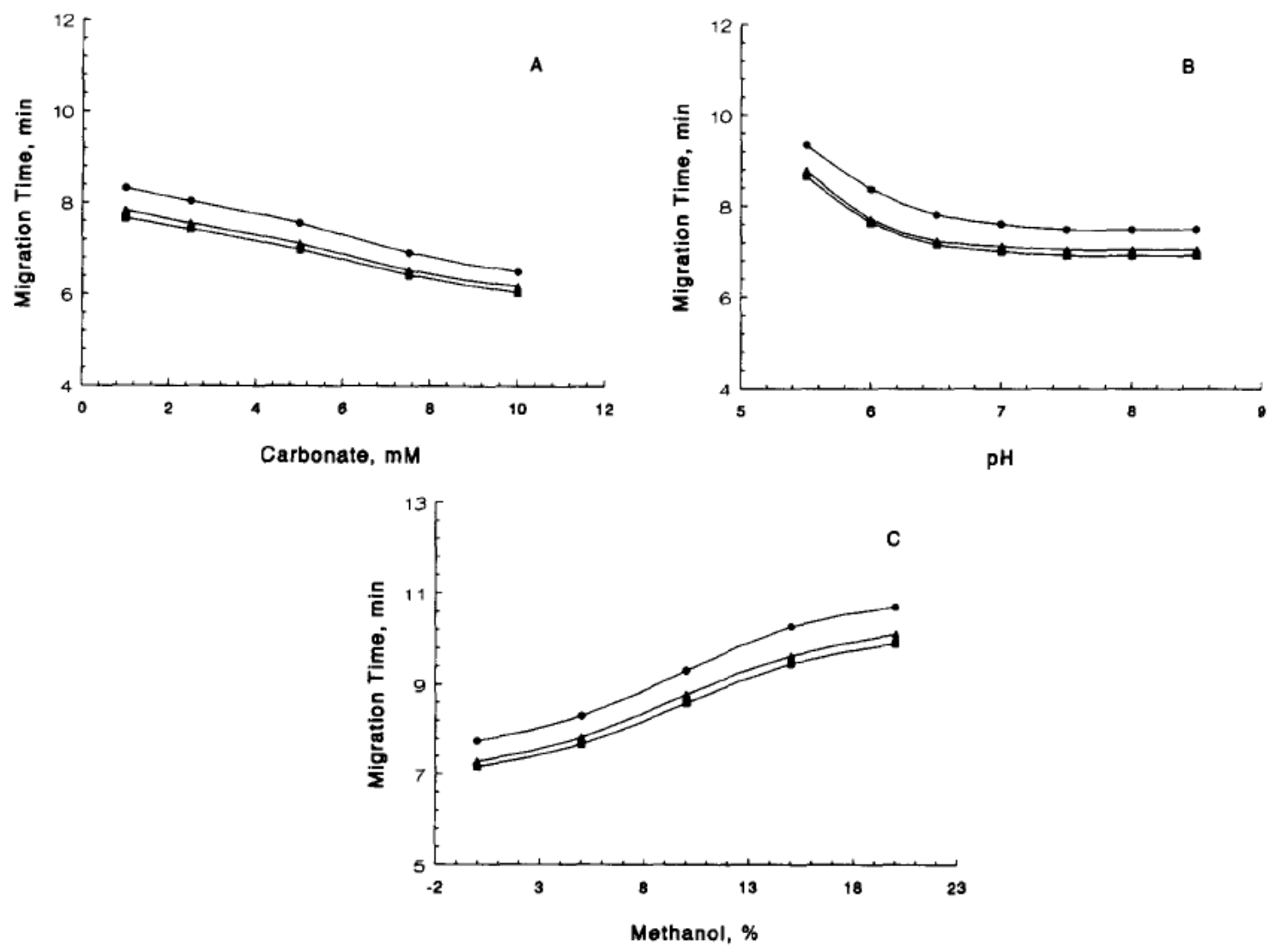

Fig. 3. Factors effecting the mobility of organic acids. (A) Carbonate concentration, (B) buffer $\mathrm{pH}$ and (C) organic modifier. Experimental

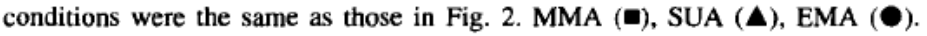


relatively unchanged with increasing phthalate concentration (data not shown). This observation may be related to the Joule heating of the run buffer, which may cause a decrease in buffer viscosity. The Ohm plot (Fig. 4) shows that the relationship between current and applied potential was non-linear at applied potentials $\geq 15 \mathrm{kV}$ and carbonate concentrations $\geq 1 \mathrm{~m} M$ (Fig. 4). This indicates that the resistance of the capillary changed as a result of inefficient heat dissipation. Although the run buffer used in this study fell in the non-linear range of the Ohm's plot, it did not effect the reproducibility of mobility because its concentration was kept unchanged in the replicate runs.

\section{Buffer $p H$}

Since it effects the net charges and the mobilities of organic acids, the buffer $\mathrm{pH}$ has the most profound effect on the migration of organic acids in CE. Fig. 3B shows that the migration times of the organic acids decreased as the buffer $\mathrm{pH}$ increased from 5.5 to 7.0. At pHs higher than 7.0, the retention times remained constant. According to Table 1, the $\mathrm{p} K_{a} s$ of EMA, SUA and MMA are within the range of 5.55 to 5.87 . Deprotonation of these organic acids advanced as the $\mathrm{pH}$ was increased from 5.5 to 7.0, resulting in increased mobilities. At pHs higher than 7.0 , the organic acids were completely deprotonated and constant mobilities were observed.

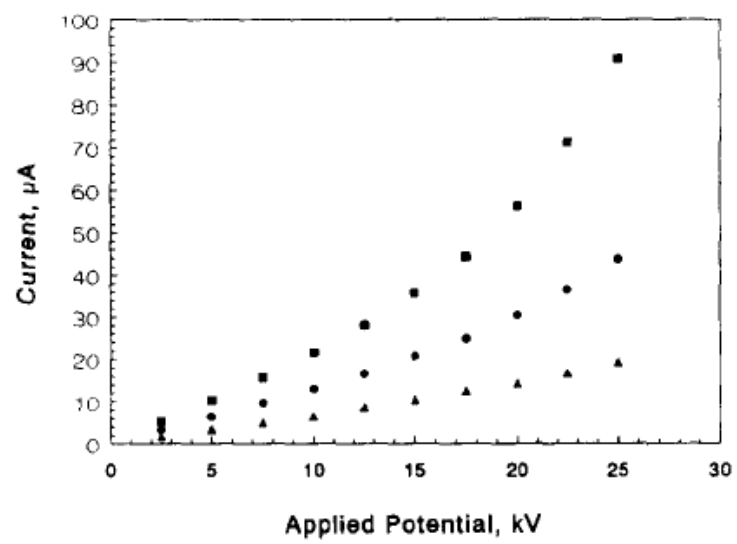

Fig. 4. Ohm's law plots for different buffer concentrations. Experimental conditions: polyacrylamide-coated capillary, 77 $\mathrm{cm} \times 100 \mu \mathrm{m}$ (I.D.); $1.0 \mathrm{~m} M$ carbonate ( $\Delta$ ); $5 \mathrm{mM}$ carbonate (O); $10 \mathrm{mM}$ carbonate $(\mathbf{\omega})$; other conditions were the same as those shown in Fig. 2C.

\section{Organic modifier}

Organic modifier may change the physicochemical properties of a run buffer. Our results indicated that the addition of methanol to run buffer extended the migration times of the organic acids (Fig. 3C), which may be caused by the increase in the viscosity of the buffer [30].

\section{Capillary columns and their analytical performances}

In addition to a polyacrylamide-coated capillary, separations of non-absorbing organic acids were achieved in both MTAB-coated and uncoated capillaries (Fig. 5). The migration order of organic acids in each type of capillary was determined by their apparent mobilities (a combined force of both electrophoretic and electroomotic flows). The peak identities in Fig. 5 were assigned by comparison of electropherograms of the mixture to those of the single organic acids and by stepwise addition of known organic acids to the mixture.

For separation in a polyacrylamide-coated capillary where electroosmosis was mostly nullified, the main force in action was the electrophoretic force that is directly proportional to the charge-to-mass ratio of an ion [31]. The migration order in Fig. 5A was that the ion with the most negative charge-tomass ratio eluted first and the ion with the least negative ratio eluted last at the outlet of the capillary (anode). Consequently, oxalate with a charge-to-mass ratio of $-1 / 44$, migrated faster than citrate which has a ratio of $-1 / 57$. Lactate and pyruvate are monocarboxylates with little difference in molecular mass, but their migration times and signal responses (see peaks 13 and 14 in Fig. 5A) were distinctively different. This is probably due to the formation of intramolecular hydrogen bonds between the hydroxyl and the carboxyl groups of a lactate ion. resulting in a lesser degree of hydration and a relatively higher effective charge of lactate than those of pyruvate. Therefore, lactate migrated faster and had a higher charge displacement ratio than pyruvate [32].

To prepare a MTAB-coated capillary, a surfactant known as myristyltrimethylammonium bromide, which has a cationic head and a hydrophobic tail, was added to the run buffer. Inside the capillary, the 

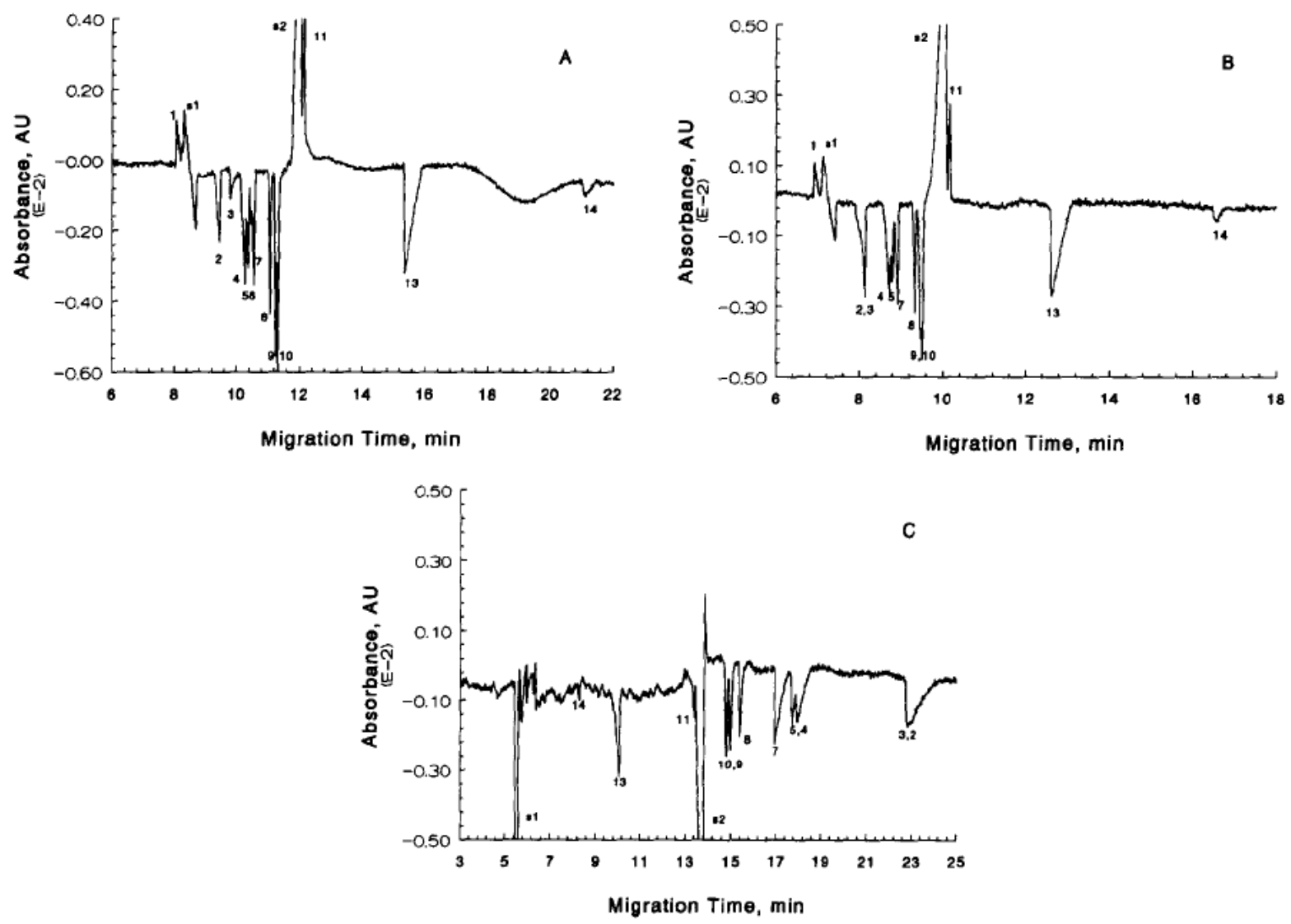

Fig. 5. Separation of organic acids on three different capillary columns. (A) Polyacrylamide-coated capillary, (B) MTAB-coated capillary and (C) uncoated capillary. Experimental conditions: capillaries, $77 \mathrm{~cm} \times 100 \mu \mathrm{m}$ I.D.; run buffers, $5 \mathrm{~m} M$ carbonate-1.5 mM phthalate at pH 7.0 (A), $5 \mathrm{~m} M$ carbonate- $1.5 \mathrm{~m} M$ phthalate/ $0.15 \mathrm{~m} M$ MTAB at $\mathrm{pH} 9.0$ (B), $5 \mathrm{~m} M$ carbonate- $1.5 \mathrm{~m} M$ phthalate at $\mathrm{pH} 8.9$ (C); other conditions were the same as those in Fig. 2. Peaks: $1=$ oxalic acid; $2=$ citric acid; $3=$ malonic acid; $4=$ tartaric acid; $5=$ methylmalonic acid; $6 \approx \alpha$-ketoglutaric acid; $7=$ succinic acid; $8=$ ethylmalonic acid; $9=$ methylsuccinic acid; $10=$ glutaric acid; $11=$ apidic acid; $12=$ methylglutaric acid; $13=$ lactic acid; $14=$ pyruvic acid; $s 1=$ system peak 1, bicarbonate ( $\mathrm{A}$ and B), water $(\mathrm{C})$; $\mathrm{s} 2=$ system peak 2, phthalate. Concentration of each organic acid, $10 \mu \mathrm{g} / \mathrm{ml}$.

positively charged heads of the surfactant dynamically formed ion-pairs with the negatively charged silanol group on the surface. If the amount of surfactant exceeded a monolayer coverage of the capillary surface, the hydrophobic tails of the surfactant in the buffer would be pushed to hydrophobic tails on the surface by the polar medium, resulting in the formation of a bilayer of the surfactant on the surface, with the cationic heads facing outwards into the aqueous solution. To secure the formation of a bilayer and complete dissociation of the organic acids, $0.15 \mathrm{mM}$ MTAB was added to the run buffer with a $\mathrm{pH}$ of 9.0. Because the dynamic coating procedure changes the surface charge of the bare capillary from negative to positive, electroosmosis in a MTAB-coated capillary adopts the same flow direction as electrophoresis of anions. As a result, the migration order of the organic acids in Fig. 5B was similar to that in the polyacrylamide-coated capillary (Fig. 5A), but with a narrower time scale.

In an uncoated capillary, the electroosmotic mobility of buffer solution was greater than the electrophoretic mobilities of the organic acids. The analyte ion with the least negative charge-to-mass ratio eluted first at the outlet cathode and the analyte ion with the most negative ratio eluted last (Fig. 5C). The migration order of the acids was a complete reversal of those in the coated capillaries (Fig. 5A 
and Fig. 5B), but with a significantly prolonged elution profile.

The analytical performances of polyacrylamidecoated, MTAB-coated and uncoated capillaries are summarized in Table 2. Among these capillaries, the polyacrylamide-coated capillary gave the best precision in retention time, displayed the highest column efficiency and provided better or comparable limits of detection to all the organic acids studied, since the electroosmotic flow was effectively suppressed and a uniform surface was created for separation. It should also be noted that although most non-absorbing analytes in indirect UV detection appear as negative peaks in electropherograms, some peaks that are close to the system peaks come out as positive signals (e.g., peaks 1 and 11 in Fig. 5) for an unknown response mechanism.

\section{Analysis of organic acids in serum and urine} samples

The developed method was applied to the analysis of citric, succinic and lactic acids in human serum
(Fig. 6A). Similarly, citric, succinic, glutaric and lactic acids were analyzed in urine (Fig. 6B). In clinical chemistry, deproteinization of biological samples is usually accomplished by alcohol (methanol, ethanol or isopropyl alcohol), or acid (trichloroacetic acid, sulfuric acid or ferric chloride-acetic acid) precipitation. The latter mode of sample pretreatment is considered inappropriate in our experimental setting due to the expected protonation of the organic acids from the acid reagents. To obtain complete deproteinization of serum with methanol, a methanol to serum ratio of $5: 1(\mathrm{v} / \mathrm{v})$ is usually required. In this work, the methanol to serum ratios of $1: 1(\mathrm{v} / \mathrm{v})$ to $5: 1(\mathrm{v} / \mathrm{v})$ have been tested for serum deproteinization. Our results indicated that there was no significant differences found in CE separations between the ratios of 1:1 and 5:1. Therefore, the ratio of $1: 1$ was adopted in this work for serum pretreatment. In urine analysis, the sample was first filtered with a $0.45-\mu \mathrm{m}$ cellulose acetate membrane filter and then diluted five times prior to sample injection. Without sample dilution, the concentration of bicarbonate found in urine ( $\mathrm{s} 1$ in Fig. 6B) would be too

Table 2

Analytical performances of three different capillary columns ${ }^{*}$

\begin{tabular}{|c|c|c|c|c|c|c|c|c|c|}
\hline \multirow[t]{2}{*}{ Analyte } & \multicolumn{3}{|c|}{$\begin{array}{l}\text { Polyacrylamide-coated capillary } \\
{ }^{\circ} N=3.44 \times 10^{5}\end{array}$} & \multicolumn{3}{|c|}{$\begin{array}{l}\text { MTAB-coated capillary } \\
N=3.09 \times 10^{5}\end{array}$} & \multicolumn{3}{|c|}{$\begin{array}{l}\text { Uncoated capillary } \\
N=1.28 \times 10^{5}\end{array}$} \\
\hline & $\begin{array}{l}\text { Migration } \\
\text { time }^{c}(\mathrm{~min})\end{array}$ & $\begin{array}{l}\text { R.S.D. } \\
(\%)\end{array}$ & $\begin{array}{l}\mathrm{LOD}^{\mathrm{e}} \\
(\mathrm{pg})\end{array}$ & $\begin{array}{l}\text { Migration } \\
\text { time (min) }\end{array}$ & $\begin{array}{l}\text { R.S.D. } \\
(\%)\end{array}$ & $\begin{array}{l}\text { LOD } \\
(\mathrm{pg})\end{array}$ & $\begin{array}{l}\text { Migration } \\
\text { time (min) }\end{array}$ & $\begin{array}{l}\text { R.S.D. } \\
(\%)\end{array}$ & $\begin{array}{l}\text { LOD } \\
\text { (pg) }\end{array}$ \\
\hline Oxalic acid & $8.16 \pm 0.02$ & 0.235 & 197 & $6.85 \pm 0.08$ & 1.26 & 197 & NA & $\mathrm{NA}$ & NA \\
\hline Citric acid & $9.52 \pm 0.03$ & 0.303 & 83.3 & $8.00 \pm 0.10$ & 1.40 & 77.4 & $22.64 \pm 0.44$ & 2.22 & 127 \\
\hline Malonic acid & $9.75 \pm 0.04$ & 0.455 & 144 & $8.04 \pm 0.09$ & 1.29 & 217 & $22.49 \pm 0.46$ & 2.31 & 217 \\
\hline Tartaric acid & $10.28 \pm 0.03$ & 0.302 & 57.0 & $8.58 \pm 0.09$ & 1.31 & 72.2 & $17.61 \pm 0.46$ & 2.98 & 127 \\
\hline Methylmalonic acid & $10.43 \pm 0.07$ & 0.744 & 67.7 & \multicolumn{2}{|c|}{$8.68 \pm 0.091 .15$} & 86.6 & $17.36 \pm 0.42$ & 2.75 & 120 \\
\hline$\alpha$-Ketoglutaric acid & $10.53 \pm 0.04$ & 0.400 & 103 & NA & NA & NA & $17.05 \pm 0.30$ & 1.98 & 217 \\
\hline Succinic acid & $10.62 \pm 0.05$ & 0.574 & 54.1 & $8.81 \pm 0.09$ & 1.18 & 61.9 & $16.78 \pm 0.19$ & 1.27 & 80.2 \\
\hline Ethylmalonic acid & $11.15 \pm 0.07$ & 0.798 & 43.3 & $9.21 \pm 0.12$ & 1.54 & 57.0 & $15.42 \pm 0.18$ & $1 . .36$ & 83.3 \\
\hline Methylsuccinic acid & $11.32 \pm 0.06$ & 0.644 & 37.3 & $9.36 \pm 0.09$ & 1.11 & 54.1 & $14.91 \pm 0.08$ & 0.650 & 67.7 \\
\hline Glutaric acid & $11.37 \pm 0.06$ & 0.569 & 34.9 & $9.42 \pm 0.09$ & 0.987 & 48.1 & $14.76 \pm 0.07$ & 0.558 & 63.7 \\
\hline Apidic acid & $12.18 \pm 0.07$ & 0.279 & 72.2 & $10.00 \pm 0.15$ & 1.76 & 72.2 & $13.22 \pm 0.15$ & 1.27 & 144 \\
\hline Methylglutaric acid & $12.21 \pm 0.07$ & 0.616 & 72.2 & $10.04 \pm 0.14$ & 1.61 & 86.6 & $13.29 \pm 0.12$ & 10.3 & 144 \\
\hline Lactic acid & $15.40 \pm 0.08$ & 0.607 & 60.2 & $12.50 \pm 0.15$ & 1.40 & 67.7 & $9.87 \pm 0.20$ & 2.30 & 72.2 \\
\hline Pyruvic acid & $20.93 \pm 0.07$ & 0.400 & 361 & $16.29 \pm 0.45$ & 3.18 & 433 & $8.19 \pm 0.07$ & 1.02 & 433 \\
\hline
\end{tabular}

Experimental conditions were the same as those in the Fig. 5.

${ }^{\mathrm{h}}$ Theoretical plate number $(\mathrm{N})$ was calculated based on the EMA peaks in Fig. 5.

"Migration time was calculated as the mean of five replicate runs plus $95 \%$ confidence interval.

${ }^{\mathrm{S}}$ Relative standard deviation (R.S.D.) of five replicate runs.

"Limit of detection (LOD) was defined as the injection volume $(57 \mathrm{nl})$ times the concentration of analyte at $S / N=3$.

NA: Not available. 

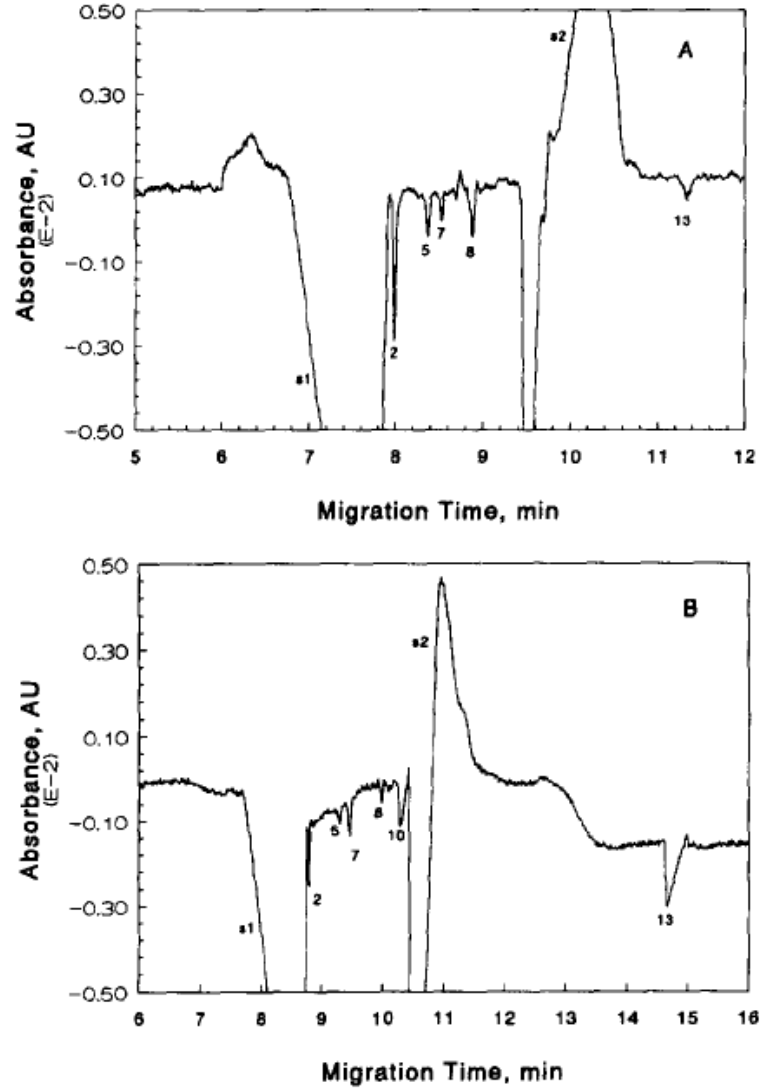

Fig. 6. Separation of organic acids in specimens of human serum (A) and urine (B). Experimental conditions: (A) capillary length, $57 \mathrm{~cm}$; injection pressure/time, $3.45 \mathrm{kPa} / 3 \mathrm{~s}$; (B) capillary length, $67 \mathrm{~cm}$; injection potential/time, $10 \mathrm{kV} / 10 \mathrm{~s}$; the other experimental conditions and peak identities were the same as those used in Fig. 5A. high to overlap with the citrate peak (peak 2 in Fig. $6 \mathrm{~B}$ ). Identification of these organic acids in serum and urine were done by sequential addition of known organic acids to the test samples and quantitations were performed using EMA as the internal standard. The results of the analyses are summarized in Table 3 , together with the measured values and the normal values cited from literature. Most of the values reported from our preliminary analyses are reconciled with the normal range reported, with the exception of succinic and glutaric acids in urine. This is a good indication that our CE method may have potential for quantitation of organic acids in biological fluids. In this preliminary study, although the level of MMA in undiluted urine could be detected, the levels of MMA in serum and diluted urine were below the limits of detection. The standard additions of MMA at a concentration of 10 $\mu \mathrm{g} / \mathrm{ml}$ to serum and diluted urine were recovered at $93 \%$ and $94 \%$, respectively (Table 3 ). Therefore, we feel that these applications warrant further development.

\section{Conclusions}

This paper has reported a simple, rapid, and reproducible $\mathrm{CE}$ method for analysis of fourteen biologically relevant, short-chain, non-UV absorbing organic acids by indirect UV detection with phthalate-carbonate buffer. The conditions that were required for optimal separation and detection sen-

Table 3

The levels of several organic acids in serum and urine detected by $\mathrm{CE}^{\mathrm{a}}$

\begin{tabular}{|c|c|c|c|c|c|}
\hline \multirow[t]{2}{*}{ Organic acid } & \multicolumn{2}{|c|}{ Serum $(\mu \mathrm{g} / \mathrm{ml})$} & \multicolumn{2}{|c|}{ Urine $(\mu \mathrm{g} / \mathrm{ml})$} & \multirow[t]{2}{*}{ Reference } \\
\hline & CE method & Normal range & CE method & Normal range $^{b}$ & \\
\hline Citric acid & 28 & $17-25$ & 75 & $70-500$ & [33] \\
\hline Methylmalonic acid & 9.3 & $0.020-0.080$ & 9.4 & $0.90-4.0$ & [3] \\
\hline Succinic acid & 6.4 & $0.18-4.4$ & 85 & $0.60-19$ & [34] \\
\hline Glutaric acid & ND & NA & 100 & $0.80-3.5$ & [34] \\
\hline Lactic acid & 11 & $30-200$ & 220 & $100-240$ & [33] \\
\hline
\end{tabular}

${ }^{2}$ Experimental conditions were the same as those in Fig. 6.

${ }^{b}$ We assume that the volume of human urine is $1400 \mathrm{ml} /$ day and that the amount of creatinine in urine is $24 \mathrm{mg} / \mathrm{kg} / \mathrm{day}$ for a $70 \mathrm{~kg}$ adult. "The levels of methylmalonic acid in the test samples were too low to be detected. The reported values were based on the standard additions of $10 \mu \mathrm{g} / \mathrm{ml}$ of the acid to the test samples.

ND: Not detected. NA: Not available. 
sitivity of organic acids have been thoroughly studied. The analytical performance of polyacrylamide-coated, MTAB-coated and uncoated capillaries has been compared and the best performance was obtained by using the polyacrylamidecoated capillary. This method has been applied to the identification and quantitation of succinic, methylmalonic, citric, glutaric and lactic acids in biological fluids, and the preliminary results have been presented. The potential use of the method in clinical analysis necessitates further studies.

\section{Acknowledgments}

A Ioan from Beckman Instruments of the data acquisition system is greatly appreciated. Hong Chen acknowledges Vytenis Gatantis and Sue Runo of Cleveland Clinic Foundation for their help in serum sample pretreatment and for their discussion of sample handling. This work was supported by the University Graduate Council of Cleveland State University.

\section{References}

11] L.M. Silverman and R.H. Christenson, in C.A. Burtis and E.R. Ashwood (Editors), Tietz Textbook of Clinical Chemistry, Saunders, Philadelphia, PA, 2nd ed., 1994, Ch. 19, p. 668.

[2] E.J. Norman, GC-MS News, 12 (1984) 120.

[3] K. Rasmussen, Clin. Chem., 35 (1989) 260.

[4] J. Schneede and P.M. Ueland, Anal. Chem., 64 (1992) 315.

[5] J. Schneede and P.M. Ueland, Clin. Chem., 39 (1993) 392.

[6] W.G. Kuhr and C.A. Monnig, Anal. Chem., 62 (1990) 400R.

[7] W.G. Kuhr and C.A. Monnig. Anal. Chem., 64 (1992) 389R.

[8] C.A. Monning and R.T. Kennedy, Anal. Chem., 66 (1994) $280 \mathrm{R}$.

[9] Y. Xu, Anal. Chem., 65 (1993) 425R.

[10] Y. Xu, Anal. Chem., 67 (1995) 463R.
[11] S. Hjerten, J. Chromatogr., 347 (1985) 191.

[12] S. Hjerten and M. Kiessling-Johansson, J. Chromatogr.. 550 (1991) 811

[13] H. Small and T.E. Miller, Anal. Chem., 54 (1982) 462.

[14] S. Hjerten, K. Elenbring, F. Kilar, J.-L. Liao, A.J. Chen, C.J. Siebert and M.-D. Zhu, J. Chromatogr., 403 (1987) 47.

[15] F. Foret, S. Fanali, L. Ossicini and P. Bocek, J. Chromatogr.. 470 (1989) 299

[16] P. Jandik and W.R. Jones. J. Chromatogr. 546 (1991) 431.

[17] Y. Ma, R. Zhang and C.L. Cooper. J. Chromatogr., 608 (1992) 93 .

[18] A. Baillet, G.A. Pianetti, M. Taverna. G. Mahuzier and D. Baylocq-Ferrier, J. Chromatogr. B, 616 (1993) 311

[19] F.S. Stover and S.S. Keffer, J. Chromatogr. A, 657 (1993) 450 .

[20] C. Quang and M.G. Khaledi, J. Chromatogr. A, 659 (1994) 459.

[21] L. Kelly and R.J. Nelson, J. Liq. Chromatogr., 16 (1993) 2103.

[22] S.P.D. Lalljie. J. Vindevogel and P. Sandra. J. Chromatogr. A. $652(1993) 563$.

[23] W.G. Kuhr and E.S. Yeung, Anal. Chem., 60 (1988) 1832.

[24] W.G. Kuhr and E.S. Yeung, Anal. Chem., 60 (1988) 2642.

[25] T.M. Olefirowicz and A.G. Ewing. J. Chromatogr.. 499 (1990) 71 ?.

[26] M.W.F. Nielen, J. Chromatogr.. 588 (1991) 321.

[27] J.A. Dean (Editor), Lange's Handbook of Chemistry. McGraw-Hill, New York, 13th ed., 1985, Ch. 5, p. 18.

[28] D.R. Lide (Editor), CRC Handbook of Chemistry and Physics, CRC Press, Boca Raton. FL, 73rd ed., 1992, Ch. 8 , p. 39.

[29] H.J. Issaq, I.Z. Atamna, G.M. Muschik and G.M. Janini, Chromatographia, 32 (1991) 155

[30] R. Kuhn and S. Hoffstetter-Kuhn, Capillary Electrophoresis: Principles and Practice, Springer-Verlag, Berlin, 1993, Ch 3, p. 100 .

[31] G.A. Pianetti, M. Taverna, A. Baillet, G. Mahuzier and D. Baylocq-Ferrier, J. Chromatogr., 630 (1993) 371.

[32] S.F.Y. Li, Capillary Electrophoresis: Principles, Practice and Applications, Elsevier, Amsterdam, 1992, Ch. 3, p. 122.

[33] S. Natelson and E. A. Natelson, Principles of Applied Clinical Chemistry: Chemical Background and Medical Applications, Vol. 1, Plenum Press, New York, NY, 1975, p. 382

[34] G. Hoffminn, S. Aramaki, E. Blum-Hoffmann, W.L. Nyhan and L. Sweetman, Clin. Chem., 35 (1989) 587 